\title{
Lipid Profile in Thyroid Autoimmunity - A Study among Reproductive Age Group Females of Central Kerala
}

\author{
Sindhu Panakkaparambil Surendranath ${ }^{1}$, Anil Palakkaparambil², \\ Suchithra Erath Thadathil ${ }^{3}$, Shibu Thadathil Sreedharan ${ }^{4}$ \\ ${ }^{1,4}$ Department of Biochemistry, Government Medical College, Thrissur, Kerala, India. ${ }^{2}$ Department of Orthopaedics, \\ District Hospital, Thrissur, Kerala, India. ${ }^{3}$ Department of Community Medicine, Government Medical College, \\ Thrissur, Kerala, India.
}

\section{ABSTRACT}

\section{BACKGROUND}

One of the most common causes of thyroid dysfunction among women is autoimmunity, especially in fertile age group. Thyroid hormone disorders are associated with a number of biochemical abnormalities including dyslipidaemia, metabolic dysfunctions, spontaneous miscarriage, and preterm delivery. Dyslipidaemia is one of the most common metabolic abnormalities present in patients with thyroid disease. The purpose of this study was to find the association between anti-thyroid peroxidase antibody (anti-TPO) and dyslipidaemia in reproductive age group females from Central Kerala.

\section{METHODS}

A total of 200 asymptomatic women, all in reproductive age group, from a tertiary hospital in Kerala participated in this study. Demographic data and detailed medical history of the participants were collected. Anti-TPO and thyroid stimulating hormone (TSH) were measured using chemiluminescence immunoassay system. Serum lipid profile was estimated using fully automated random-access clinical chemistry analyser EM - 360. Continuous variables were compared between the groups using Mann-Whitney U-test. P value lesser than 0.05 was considered as statistically significant.

\section{RESULTS}

The mean age of the subjects was $32.92 \pm 11.82$ years. A total of 47 participants $(23.5 \%)$ were anti-TPO positive. Abnormality in lipid profile was present in 72.34 $\%(\mathrm{~N}=34)$ of the anti-TPO positive participants. In the anti-TPO positive group, $51.06 \%$ of the participants had hypercholesterolemia. In the anti-TPO positive group, anti-TPO levels show a statistically significant correlation with total cholesterol and triglyceride levels $(\mathrm{P}=0.07$ and $\mathrm{P}<0.01)$. A total of $9 \%(\mathrm{~N}=18)$ had thyroid stimulating hormone (TSH) values greater than normal range $(0.34-$ $4.25 \mu \mathrm{IU} / \mathrm{mL}$ ) suggesting presence of hypothyroidism. TSH values were also significantly associated with lipid profile in the anti-TPO positive group. Both thyroid autoimmunity and dyslipidaemia can affect fertility, pregnancy and other reproductive outcomes.

\section{CONCLUSIONS}

Women should be screened for autoimmune antibodies and associated biochemical abnormalities to estimate and reduce the risk of cardiovascular morbidity, negative pregnancy outcomes and infertility.

\section{KEY WORDS}

Thyroid Autoimmunity, Anti-TPO Antibody, Dyslipidaemia
Corresponding Author: Dr. Sindhu Panakkaparambil Surendranath, Associate Professor, Department of Biochemistry, Government Medical College, Thrissur, Kerala, India.

E-mail: sindhuanilps@yahoo.com

DOI: $10.14260 /$ jemds/2021/656

How to Cite This Article:

Surendranath SP, Palakkaparambil A, Thadathil SE, et al. Lipid profile in thyroid autoimmunity - a study among reproductive age group females of Central Kerala. J Evolution Med Dent Sci 2021;10(37):3231-3236, DOI: 10.14260/jemds/2021/656

Submission 12-05-2021,

Peer Review 23-08-2021,

Acceptance 30-08-2021,

Published 13-09-2021.

Copyright (C) 2021 Sindhu Panakkaparambil Surendranath et al. This is an open access article distributed under Creative Commons Attribution License [Attribution 4.0 International (CC BY 4.0)] 


\section{BACKGROUND}

Thyroid dysfunctions, namely hypothyroidism or hyperthyroidism, are the most common metabolic disorder in general population, and can be detected in a subclinical or overt form. ${ }^{1}$ Autoimmunity is one of the most frequent cause of thyroid dysfunction in women of reproductive age. About 5 - $15 \%$ of euthyroid women have thyroid antibodies like antithyroid peroxidase antibody and are at increased risk of developing thyroid dysfunction. ${ }^{2}$ The presence of anti-TPO antibodies is relatively high in women of child bearing age. ${ }^{3}$

Thyroid dysfunctions remain asymptomatic in most of the cases and hence, American Thyroid Association has recommended routine population screening for early detection and treatment of the condition. Subclinical hypothyroidism has a high conversion rate into overt hypothyroidism. ${ }^{4}$

Thyroid hormone disorders are associated with a number of biochemical abnormalities due to the effect of thyroid hormones in all major metabolic pathways. These include dyslipidaemia, metabolic dysfunctions, spontaneous miscarriage and preterm delivery. ${ }^{5}$

Thyroid dysfunction is also a known cause of infertility along with many other factors like hyperprolactinemia. Autoimmune thyroiditis is prevalent in women with polycystic ovary syndrome, specifying the importance of screening for anti-TPO antibodies in women, especially in their reproductive age. ${ }^{6}$

Thyroid hormones have a major effect in all aspects of lipid metabolism and is known to cause a number of qualitative and quantitative changes in lipids. Dyslipidaemia is one of the most common metabolic abnormalities in patients with thyroid diseases. Existing data support that thyroid dysfunctions are associated with increased cardiovascular risk due to hemodynamic alterations and an elevated risk of atherosclerosis. In thyroid dysfunctions, lipid profile changes are established, however, lipid profile changes in thyroid autoimmunity is not well known. There is paucity of data on biochemical profile and prevalence of thyroid dysfunctions from India. Data from Kerala is negligent with respect to anti-TPO antibodies and its association with different biochemical abnormalities.

The aim of this study is to find association between antiTPO antibody and dyslipidaemia in reproductive age group females from Central Kerala. The objectives of the study are 1). To determine the changes in serum lipid profiles and thyroid autoimmunity in females belonging to the fertile age group and 2). To find the association between these two parameters in these women.

\section{METHODS}

This study is cross sectional study conducted on 200 asymptomatic females in reproductive age group, all of whom were either students or staff of a tertiary healthcare centre. The study was conducted from September 2015 to August 2016.

\section{Inclusion Criteria}

Adult female (students or staff) of a tertiary healthcare center in Central Kerala

\section{Exclusion Criteria}

Potential participants were excluded if they were-

- Pregnant.

- Had already diagnosed thyroid disease

- Currently receiving thyroid medications

- Currently on anti-lipidaemic medications

- Not willing to participate in the study

Enrolment was done based on the inclusion and exclusion criteria. Study subjects were counselled separately about the study and a written consent was procured from them. Demographic data like age was recorded along with a detailed medical and family history using a semi-structured questionnaire. General physical examination including vitals (temperature, pulse, blood pressure, etc) were also noted. Serum samples of participants were processed for lipid profile, TSH and anti-TPO antibody. Venous blood samples were collected in the morning between 7:00 am to 10:00 am after an 8 - 12 hour fast, and then promptly centrifuged and analysed. The levels of serum TSH and anti TPO antibody were determined in all subjects on the same day of blood sampling. Institutional Ethics Committee of Thrissur Medical College Hospital approved the study.

Thyroid stimulating hormone and anti-TPO were measured using chemiluminescence immunoassay systemRoche Cobas E411. The concentrations of total cholesterol (TC), triglyceride (TG), low-density lipoprotein cholesterol (LDL-C), and high-density lipoprotein cholesterol (HDL-C) were estimated using fully automated random access clinical chemistry analyser EM - 360. Appropriate calibrators were used for validating the test.

Serum lipids were classified as per National Cholesterol Education Program-Adult Treatment Panel III Guidelines. ${ }^{7}$ According to these guidelines, hypercholesterolemia is defined as total cholesterol (TC) value $>200 \mathrm{mg} / \mathrm{dl}$, high lowdensity lipoprotein (LDL) as > $100 \mathrm{mg} / \mathrm{dl}$, hypertriglyceridemia as triglyceride (TG) value $>150 \mathrm{mg} / \mathrm{dl}$, and low high-density lipoprotein (HDL) as $<40 \mathrm{mg} / \mathrm{dl}^{7}$ Dyslipidaemia is defined as the presence of one or more than one abnormal serum lipid values. For analyses of anti-TPO antibodies, the reference value taken was $<35 \mathrm{IU} / \mathrm{mL}$. And for serum TSH, $0.34-4.25 \mu \mathrm{IU} / \mathrm{mL}$ was considered as the reference range. Hypothyroidism state of the participants was analysed on the basis of TSH level alone due to economic constraints.

Participants were grouped into two on the basis of antiTPO levels - anti-TPO positive and anti-TPO negative. Participants with anti-TPO antibody values above $35 \mathrm{IU} / \mathrm{mL}$ were considered anti-TPO positive. Exploratory analysis was done using EPI Info version1. TSH and anti-TPO levels were analysed using multivariate linear regression models after log transformation due to skewness of their distribution in their original scale. Continuous variables were presented as mean \pm standard deviation, and categorical variables were presented as absolute numbers and percentage. MannWhitney U-test was used for comparison of continuous variables between the two groups. Differences between 
groups were assessed with chi-square or Fisher's exact test for categorical variables as appropriate. $\mathrm{P}<0.05$ was taken as statistically significant.

\section{RESULTS}

In this cross-sectional study, 200 participants from the department were evaluated for the presence of anti-thyroid peroxidase antibody and serum lipid profile and TSH. The mean age (mean \pm SD) of the participating women were 32.92 \pm 11.82 years. More than half of the participants in the study were staff of the department, while the rest were students. About $17 \%$ of the participants had a family history of thyroid disorders. Most of them had regular menstrual cycle and only $7 \%$ reported to have irregularities in periods.

Anti-TPO had a high mean value among the participants of the study $(68.12 \mathrm{IU} / \mathrm{mL})$. A total of 47 participants $(23.5$ $\%)$ were anti-TPO positive. Mean age of the anti-TPO positive group was $34.56 \pm 12$ years, while that of anti-TPO negative group was $32.43 \pm 11.77$ years.

\begin{tabular}{|cc|}
\hline \multicolumn{2}{|c|}{ Anti-thyroid Peroxidase Distribution } \\
Anti-TPO & n (\%) \\
$>35$ & $47(23.5 \%)$ \\
$<35$ & $153(76.5 \%)$ \\
Total & $200(100 \%)$ \\
\hline Table 1. Anti-TPO Distribution among the Participants \\
\hline
\end{tabular}

The mean values of TC among the participants was $198.17 \mathrm{mg} / \mathrm{dL}$, while that of TG was $105.15 \mathrm{mg} / \mathrm{dL}$. Average LDL in the study group was $118.88 \mathrm{mg} / \mathrm{dL}$ and HDL was $58.38 \mathrm{mg} / \mathrm{dL}$. Lipid abnormality was present in $72.34 \%(\mathrm{~N}=$ 34) of the anti-TPO positive participants. In the anti-TPO positive group, $51.06 \%(\mathrm{~N}=24)$ of the participants had hypercholesterolemia, whereas in the anti-TPO negative group, $40.79 \%(\mathrm{~N}=62)$ had hypercholesterolemia which was not statistically significant $(\mathrm{P}=0.65)$. In anti-TPO positive group, $6.38 \%$ had hyperglyceridaemia; whereas in the anti-TPO negative group, $5.26 \%(\mathrm{~N}=8)$ had hyperglyceridaemia. There was a significant association between the triglycerides and anti-TPO antibodies $(\mathrm{P}=0.03)$. Likewise, in anti-TPO positive group, $14.9 \%(\mathrm{~N}=7)$ had hyper LDL cholesterol (LDL-C); while in TPO negative, one fourth of the patients had hyper LDL-C which was not statistically significant. None of the participants from antiTPO positive group had low HDL-cholesterol (HDL-C), while $3.9 \%$ of the anti-TPO negative group had low HDL-C.

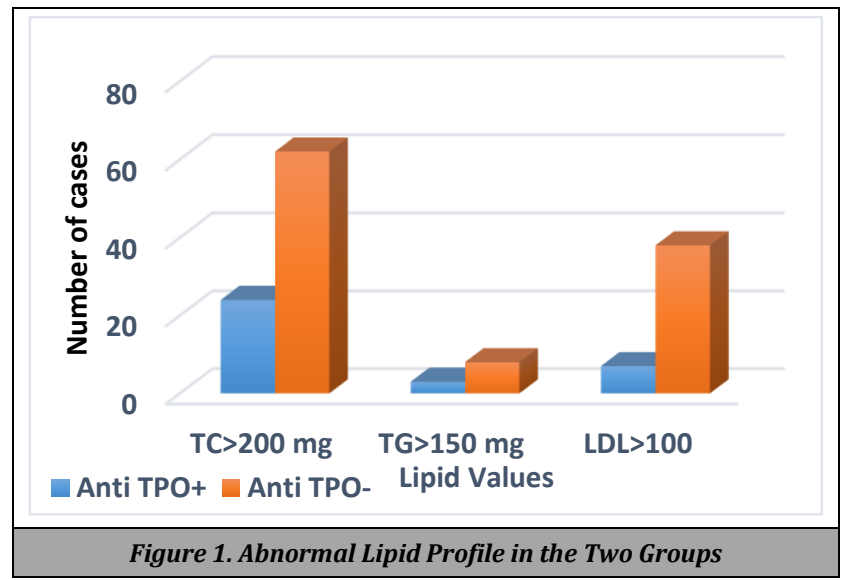

(anti-TPO - anti thyroid peroxidase antibody; TC - total cholesterol; TG- Total glycerides; LDL-C - LDL cholesterol; HDL-C - HDL-Cholesterol).

\begin{tabular}{|c|c|c|c|}
\hline & Anti TPO +ve & Anti TPO -ve & P Value \\
\hline $\mathrm{TC}>200 \mathrm{mg}$ & 24 (51.06 \%) & $62(40.79 \%)$ & 0.3 \\
\hline $\mathrm{TG}>150 \mathrm{mg}$ & $3(6.38 \%)$ & $8(5.26 \%)$ & $0.03^{*}$ \\
\hline LDL-C $>100$ & $7(14.9 \%)$ & $38(25 \%)$ & 0.32 \\
\hline $\mathrm{HDL}<40$ & 0 & $6(3.94 \%)$ & 0.007 \\
\hline Hyperlipidaemia & $34(72.34 \%)$ & $114(75 \%)$ & \\
\hline \multicolumn{4}{|c|}{$\begin{array}{l}\text { Table 2. Correlation between Abnormal Lipid Profile and Anti-TPO } \\
\text { Antibodies }\end{array}$} \\
\hline
\end{tabular}

(Anti-TPO - anti thyroid peroxidase antibody; TC - total cholesterol; TG- Total glycerides; LDL-C - LDL cholesterol; HDL-C - HDL-Cholesterol).

Among the participants with anti-TPO positivity, more than half (51.06\%) had TC values higher than $200 \mathrm{mg}$ indicating hypercholesterolaemia. About $15 \%(\mathrm{~N}=7)$ had serum LDL-C levels higher than $150 \mathrm{mg}$, while around $6 \%$ had higher TG levels, both of which indicate hyperlipidaemia. A comparison of lipid levels with anti-TPO levels in anti-TPO positive group shows a statistically significant correlation between antibody levels and total cholesterol and triglyceride levels $\left(\mathrm{P}=0.07^{*}\right.$ and $\mathrm{P}<0.01^{*}$ ). LDL-C and HDL-C did not show any significant correlation between the two parameters in this group.

In the anti-TPO negative group of participants, $40.79 \%$ had hypercholesterolaemia indicated by TC values greater than $200 \mathrm{mg}$. One fourth of the subjects in this group had high serum LDL-C levels, $5.26 \%$ had high levels of TG in the serum. TC and LDL-C values of the anti-TPO negative group did not show any significant association with anti-TPO antibodies. Total glycerides showed a significant correlation with antibody levels in anti-TPO negative group also $(\mathrm{P}<$ $\left.0.05^{*}\right)$.

A total of $9 \%(\mathrm{~N}=18)$ had TSH values greater the normal range $(0.34-4.25 \mu \mathrm{IU} / \mathrm{mL})$ suggesting presence of hypothyroidism. Mean age (mean \pm SD) of this group was $38.89 \pm 10.59$ years. Mean TSH value was $9.69 \pm 11.37 \mu$ $\mathrm{IU} / \mathrm{mL}$. More than half of the participants in this group $(\mathrm{N}=$ 10) had high anti-TPO levels (mean \pm SD $=192.68 \pm 244.28$ $\mathrm{IU} / \mathrm{mL}$ ). TSH and anti-TPO antibodies had a statistically significant correlation $\left(\mathrm{R}=0.192, \mathrm{P}=0.006^{*}\right)$. There was a statistically significant correlation between TSH and anti-TPO when the participant had a family history of thyroid disorders $\left(\mathrm{R}=0.630, \mathrm{P}=0.028^{*}\right)$

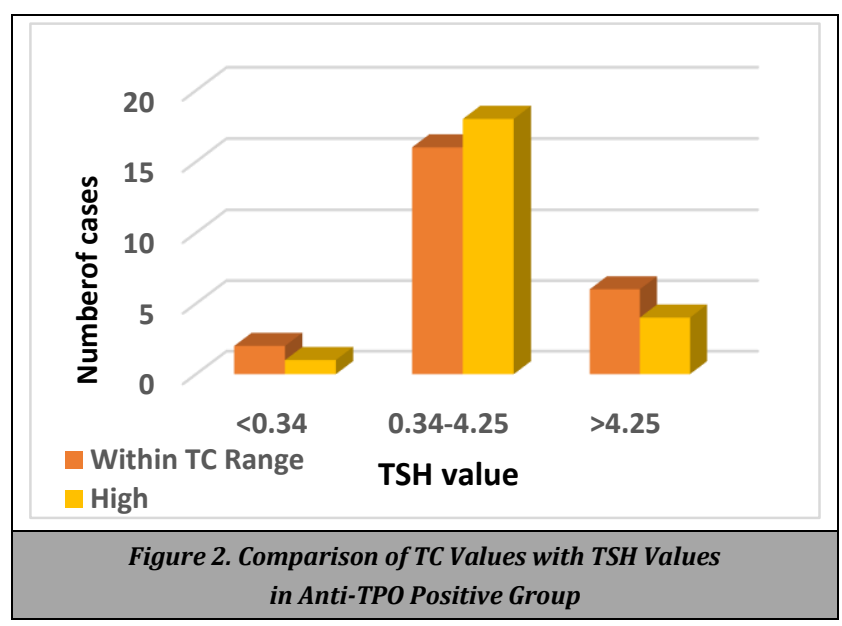


(Anti-TPO - anti thyroid peroxidase antibody; TC - total cholesterol; TSH - thyroid stimulating hormone).

Among the anti TPO positive group participants, $34 \%$ (N =16) had TSH values and TC values within normal range, but in $13 \%(\mathrm{~N}=6)$ of them TSH values were $>4.25 \mu \mathrm{IU} / \mathrm{mL}$ even when TC values were within acceptable range. In the same group, $38 \%(\mathrm{~N}=18)$ had high TC values with normal TSH values, whereas $9 \%(\mathrm{~N}=4)$ had both TSH and TC values higher than normal. While comparing the TSH values with serum TG levels, more than half of the participants (55\%) had normal values for both TSH and TG. A total of 6 participants (13\%) showed higher values of TSH when serum TG levels were well within normal range. In this group of anti-TPO positive participants, $17 \%(\mathrm{~N}=8)$ recorded high TG values but had normal TSH levels. Among the 47 anti-TPO positive participants, $9 \%(\mathrm{~N}=4)$ had both TSH and TG values higher than normal. Among the 34 participants with normal TSH values, 11 (23\%) of them had serum LDL-C values well within range, while close to $50 \%(\mathrm{~N}=23)$ had high LDL-C levels. A total of 10 participants (21\%) who had high levels of TSH, 4 (9\%) had serum LDL-C values while the rest $(21 \%)$ had high serum LDL-C levels.

Statistically significant association was present between TSH values and serum TC levels in the anti-TPO positive group $(\mathrm{R}=0.028, \mathrm{P}<0.05)$. TSH levels were also associated with TG levels in this group of participants $(\mathrm{R}=0.002, \mathrm{P}<$ 0.05). LDL-C levels in the same group were statistically associated with TSH values $(\mathrm{R}=0.05, \mathrm{P}<0.05)$ too. None of the participants had lower than normal serum levels of HDLC.

\begin{tabular}{|c|c|c|c|c|c|}
\hline & & & TSH Range & & \\
\hline & & $<0.34$ & $0.34-4.25$ & $>4.25$ & Total \\
\hline & Within TC range & 2 & 16 & 6 & 24 \\
\hline Total & High & 1 & 18 & 4 & 23 \\
\hline & Total & 3 & 34 & 10 & 47 \\
\hline & Within TG range & 2 & 26 & 6 & 34 \\
\hline Total glycerides & High & 1 & 8 & 4 & 13 \\
\hline & Total & 3 & 34 & 10 & 47 \\
\hline & Within TG range & 0 & 11 & 4 & 15 \\
\hline Total LDL-C & High & 3 & 23 & 6 & 32 \\
\hline & Total & 3 & 34 & 10 & 47 \\
\hline
\end{tabular}

(Anti-TPO - anti thyroid peroxidase antibody; TC - total cholesterol; TG- Total glycerides; LDL-C - LDL cholesterol; TSH - thyroid stimulating hormone)

\section{DISCUSSION}

Thyroid dysfunctions related to autoimmunity are one of the most common causes of thyroid diseases. ${ }^{8}$ In general population, $8-27 \%$ are reported to have anti-TPO antibodies and a high titre of these antibodies is present in $89.9 \%$ of patients with autoimmune thyroid disorders. ${ }^{9}$ One of our earlier studies showed that one in four women in the reproductive age to be having higher levels of anti-TPO antibodies. ${ }^{3}$ Most of these women were euthyroid and asymptomatic. Anti-TPO positivity can progress to overt hypothyroidism and decrease the quality of life in women. ${ }^{10}$ While many studies are available regarding the effects of antiTPO antibodies in subclinical-hypothyroid women, very few relate to euthyroid fertile females. A study on 1000 euthyroid Indian women showed a higher prevalence of infertility, anaemia and pre-term delivery in anti-TPO positive euthyroid group. ${ }^{11}$ Anti-TPO antibodies can cross the placenta, and also lead to vasculo-placental complications including postpartum haemorrhage, placental abruption, postpartum thyroiditis and pre-eclampsia. ${ }^{12} \mathrm{New}$-born babies are susceptible to thyroid dysfunctions like hypothyroidism as these thyroid antibodies cross the placental barrier. TSH values are also known to be elevated in women with infertility when compared to control population. ${ }^{13}$ Thyroid autoantibodies were indicated as a marker of at-risk pregnancy in a study conducted in 552 women in their first trimester of pregnancy. ${ }^{14}$ Women in thyroid autoantibodypositive group had a higher rate of miscarriage $(17 \%)$ when compared to those who did not have thyroid autoantibodies (8.4\%). Moreover, in a cross-sectional study conducted in 187 women with unexplained infertility, TSH levels were found to be high when compared to control group. ${ }^{15}$

Thyroid dysfunctions may cause symptoms that affect the quality of life of a woman. Thyroid disorders are associated with dyslipidaemia and this is known to confer risk of cardiovascular diseases.16,17,18,19 Mustaq et al. reported an increase in serum TC, LDL-C, HDL-C, or TG in patients with thyroid dysfunction. ${ }^{20}$ Similarly, dyslipidaemia was significantly associated with anti-TPO positivity in other studies, especially in women with thyroid dysfunction. ${ }^{21} \mathrm{~A}$ recent retrospective study investigating the association of serum lipids and anti-thyroid antibody positivity in 7688 participants with normal TSH levels shows positive association between thyroid antibodies and increasing LDL-C and decreasing HDL-C $(\mathrm{P}<0.05){ }^{22}$ This large study indicates that serum lipids may be predictors of thyroid autoimmunity even in women with normal TSH levels.

TSH is a pituitary gland hormone that plays a significant role in the normal functioning of thyroid glands. Increased TSH levels may also lead to dyslipidaemia. In our study, TSH levels, though within normal range, were higher in anti-TPO positive group subjects when compared to that of anti-TPO negative group. This increase in the TSH values may be due to the elevated risk of thyroid dysfunction in anti-TPO positive people. Studies from Kerala are negligent regarding the degree of lipid changes in thyroid dysfunctional groups. This study was an attempt to determine the association of antiTPO antibodies and dyslipidaemia in reproductive age women with high levels of anti-TPO antibodies.

In this cross-sectional study, triglycerides were significantly associated with anti-TPO antibodies in the group with thyroid antibodies when compared to the anti-TPO negative group. Other studies, most of which were conducted on subclinical hypothyroid women, also observed significantly high serum values of triglycerides in patients with increased anti-TPO antibodies. ${ }^{23,24}$ Lai et al. in a study on 1534 Chinese adults with subclinical hypothyroidism, observed similar increase in triglycerides. ${ }^{25}$ But in an Indian study conducted by Kumar et al. in Uttar Pradesh, triglycerides were only marginally elevated in patients with subclinical hypothyroidism. ${ }^{26}$ Anti-TPO antibodies were found to have a statistically significant association with hyperlipidaemia in yet another Indian study conducted by Jaseem et al. on women with thyroid dysfunction. ${ }^{27}$ Our study shows that serum TSH levels also have a significant association with lipid levels, including TC, TG, LDL-C, in the anti-TPO positive group. Similar association was recorded by 
Saranya in 96 patients with thyroid dysfunction in Chennai. ${ }^{28}$ HDL-C did not have any significant association with thyroid autoimmunity in the participants of our study which was similar to the results presented by Hiregoudar et al. in a study conducted in Odisha, India. ${ }^{15}$

Variations in thyroid hormone affects the functioning of cardiovascular system and, thus, patients with thyroid dysfunctions or high levels of anti-TPO antibodies also have an elevated risk of developing coronary artery disease (CAD). ${ }^{29}$ Risk of CAD and all-cause mortality was higher in patients with thyroid disorders. ${ }^{30}$ Besides the evident effect on cardiovascular diseases, studies show dyslipidaemia as a major determinant of infertility. ${ }^{31,32}$ Importance of lipid homeostasis in female fertility is reported in a prospective cohort study conducted in US. ${ }^{33}$ In an observational study on fertile females in Aurangabad, India, significant correlation was observed between dyslipidaemia, fertility and thyroid dysfunctions. ${ }^{34}$ About $22 \%$ of the participants in this study by Vikas et al. had menstrual irregularities while $10.5 \%$ had infertility. Elevated levels of triglycerides before pregnancy are associated with increased risk of pregnancy complications including pre-eclampsia and gestational diabetes mellitus. ${ }^{35}$

Thus, thyroid autoimmunity is known to have association with pregnancy loss, pre-term birth, rate of miscarriage and even infertility. Further, dyslipidaemia is also a known cause for infertility and other pregnancy complications. Given the potential association of thyroid autoimmunity and dyslipidaemia with pregnancy outcomes and infertility, it is of prime importance to screen pregnant women for thyroid antibodies. And if found positive for this antibody, they must be examined for associated conditions, especially dyslipidaemia to improve fertility and pregnancy, when necessary. Screening for and treatment of thyroid dysfunction in fertile, asymptomatic women can lead to clinically important benefits. More studies, preferably largescale population-based studies, are needed to assess the risk of thyroid autoimmunity and associated biochemical changes on fertility rate and other reproductive outcomes.

\section{CONCLUSIONS}

Association between autoimmune antibodies like anti-TPO antibodies and negative pregnancy outcomes are known from different studies. Abnormal lipid profile is also associated with infertility and pregnancy complications in females, including euthyroid women. Given these associations of biochemical profile of women with fertility and other reproductive outcomes, it is important to screen reproductive age women for autoimmune antibodies and dyslipidaemia for better understanding, prevention, and treatment of infertility and cardiovascular morbidities.

\section{Limitations of This Study}

Small sample size and differences in baseline characteristics of the participants are two limitations of this study.

Data sharing statement provided by the authors is available with the full text of this article at jemds.com.

Financial or other competing interests: None.
Disclosure forms provided by the authors are available with the full text of this article at jemds.com.

\section{REFERENCES}

[1] Duntas LH. Thyroid disease and lipids. Thyroid 2002;12(4):287-93.

[2] Longo DL, Fauci AS, Kasper DL, et al. Disorders of thyroid gland. Harrison's Principles of Internal Medicine. $18^{\text {th }}$ edn. New York: McGraw-Hill Publication 2011: p. 291722.

[3] Sindhu PS, Pushpalatha M, Anil P. Anti-thyroid peroxidase antibody prevalence in reproductive age group females - a study from Central Kerala, India. J Evid Based Med Healthcare 2017;4(23):1336-40.

[4] Caparevic Z, Bojkovic G, Stojanovic D, et al. Dyslipidaemia and subclinical hypothyroidism. Med Pregl 2003;56(5-6):276-80.

[5] Guyton AC, Hall JE. The thyroid metabolic hormones. Textbook of Medical Physiology. 10 ${ }^{\text {th }}$ edn. New York: W.B Sanders Company, 2000: p. 858-68.

[6] Salehpour S, Saharkhiz N, Moeini A, et al. Anti-thyroid peroxidase antibodies in women with polycystic ovary syndrome. Iran J Reprod Med 2013;11(12):1031-2.

[7] National Cholesterol Education Program (NCEP) Expert Panel on Detection, Evaluation and Treatment of High Blood Cholesterol in Adults (Adult Treatment Panel III). Third Report of the National Cholesterol Education Program (NCEP) Expert Panel on Detection, Evaluation, and Treatment of High Blood Cholesterol in Adults (Adult Treatment Panel III) final report. Circulation 2002;106(25):3143-421.

[8] Jeena EJ, Malathi M, Sudeep K. A hospital-based study of anti-TPO titer in patients with thyroid disease. Muller J Med Sci Res 2013;4(2):74-7.

[9] Knobel M, Barca F, Pedrinola F, et al. Prevalence of antithyroid peroxidase antibodies in autoimmune and nonautoimmune thyroid disorders in a relatively low iodine environment. J Endocrin Invest 1994;17(11):837-42.

[10] Deshmukh V, Behl A, lyer V, et al. Prevalence, clinical and biochemical profile of subclinical hypothyroidism in normal population in Mumbai. Indian J Endocrinol Metab 2013;17(3):454-9.

[11] Meena M, Chopra S, Jain V, et al. The effect of anti-thyroid peroxidase antibodies on pregnancy outcomes in euthyroid women. J Clin Diagn Res 2016;10(9):QC04QC07.

[12] Seror J, Amand G, Guibourdenche J, et al. Anti-TPO antibodies diffusion through the placental barrier during pregnancy. PLoS One 2014;9(1):e84647.

[13] Jokar OT, Fourman LT, Lee H, et al. Higher TSH levels within the normal range are associated with unexplained infertility. J Clin Endocrinol Metab 2018;103(2):632-9.

[14] Stagnaro-Green A, Roman SH, Cobin RH, et al. Detection of at-risk pregnancy by means of highly sensitive assays for thyroid autoantibodies. J Am Med Assoc 1990;264(11):1422-5.

[15] Hiregoudar MB, Mohanty PK, Tripaty S, et al. Clinical profile and lipid abnormalities in subclinical and overt primary hypothyroidism. Int J Res Med Sci 2019;7(6):2003-8. 
[16] Després JP, Golay A, Sjöström L, et al. Effects of rimonabant on metabolic risk factors in overweight patients with dyslipidaemia. New Engl J Med 2005;353(20):2121-34.

[17] Chiasson JL, Josse RG, Gomis R, et al. Acarbose treatment and the risk of cardiovascular disease and hypertension in patients with impaired glucose tolerance. J Am Med Assoc 2003;290(4):486-94.

[18] O'Brien T, Dinneen SF, O'Brien PC, et al. Hyperlipidemia in patients with primary and secondary hypothyroidism. Mayo Clin Proc 1993;68(9):860-6.

[19] Hueston WJ, Pearson WS. Subclinical hypothyroidism and the risk of hypercholesterolemia. Ann Fam Med 2004;2(4):351-5.

[20] Mushtaq S, Ishaq S, Rashid T, et al. Dyslipidaemia in thyroid disorders. Indo Am J Pharma Res 2015;5(11):3439-43.

[21] Srivastava VK, Singh H. Association of thyroid peroxidase antibody and dyslipidaemia in subclinical hypothyroidism. J Family Med Prim Care 2017;6(1):63-8.

[22] Li J, Wang Z, Liu H, et al. Serum lipids are novel predictors for thyroid autoimmunity in the general population with normal TSH levels from a crosssectional study. Endocrine 2021;73(2):331-8.

[23] Bandyopadhyay SK, Basu AK, Pal SK, et al. A study on dyslipidaemia in subclinical hypothyroidism. J Indian Med Assoc 2006;104(11):622-4, 626.

[24] Laway BA, War FA, Shah S, et al. Alteration of lipid parameters in patients with subclinical hypothyroidism. Int J Endocrinol Metab 2014;12(3):e17496.

[25] Lai Y, Wang J, Jiang F, et al. The relationship between serum thyrotropin and components of metabolic syndrome. Endocr J 2011;58(1):23-30.

[26] Kumar M , Rajpoot RS. A study of lipid profile in patients of subclinical hypothyroidism in rural area of Western Uttar Pradesh, India. Int J Res Med Sci 2016;4(8):3245-9.
[27] Jaseem T, Hegde A, Chakrapani M, et al. Hemoglobin, Vitamin D and lipids in subclinical hypothyroid patients - do the anti -thyroid autoantibodies titer matters? Bio Med Pharmaco J 2017;10(3):1175-80.

[28] Sharanya M. A dissertation on dyslipidaemia in subclinical hypothyroidism [dissertion]. Masters Thesis. Tamilnadu Dr M.G.R. Medical University: Chennai, 2016. (Updated 2016; Cited 2021 June 08). http://repositorytnmgrmu.ac.in/10507/1/200100416saranya_masilama ni.pdf

[29] Shekhar R, Chowdary NV, Das MC, et al. Prevalence of subclinical hypothyroidism in coastal Andhra Pradesh. Biomed Res 2011;22(4):471-4.

[30] McQuade C, Skugor M, Brennan DM, et al. Hypothyroidism and moderate subclinical hypothyroidism are associated with increased all-cause mortality independent of coronary heart disease risk factors: a pre CIS database study. Thyroid 2011;21(8):837-43.

[31] Broughton DE, Moley KH. Obesity and female infertility: potential mediators of obesity's impact. Fertil Steril 2017;107(4):840-7.

[32] Pugh SJ, Schisterman EF, Browne RW, et al. Preconception maternal lipoprotein levels in relation to fecundability. Hum Reprod 2017;32(5):1055-63.

[33] Schisterman EF, Mumford SL, Browne RW, et al. Lipid concentrations and couple fecundity: the LIFE study. The Journal of Clinical Endocrinology \& Metabolism 2014;99(8):2786-94.

[34] Vikas R, Harsh S, Kavitha U. Link between infertility, overweight and subclinical hypothyroidism. Int J Health Sci and Res 2020;10(2):10-17.

[35] Baumfeld Y, Novack L, Wiznitzer A, et al. Correction: preconception dyslipidemia is associated with development of preeclampsia and gestational diabetes mellitus. PLoS One 2015;10(11):e0142462. 